\title{
Multimodal Neurons in the Lamb Solitary Nucleus
}

\section{Responses to Chemical, Tactile, and Thermal Stimulation of the Caudal Oral Cavity and Epiglottis ${ }^{a}$}

\section{ROBERT D. SWEAZEY AND ROBERT M. BRADLEY}

\author{
Department of Oral Biology \\ School of Dentistry \\ The University of Michigan \\ Ann Arbor, Michigan 48109
}

The receptor areas of the soft palate, caudal tongue, and epiglottis are important for the elicitation and control of ingestive behavior and upper airway reflexes. The afferent fibers that innervate these structures terminate primarily in the nucleus of the solitary tract (NST) or the spinal trigeminal nucleus. ${ }^{1}$ To better understand the role of the NST in the integration of information from these separate receptor populations, we have recorded neural responses to mechanical, thermal and chemical stimulation.

\section{METHODS}

Experiments were performed on 31 anesthetized Suffolk lambs, aged 38-70 days, weighing $9-23 \mathrm{~kg}$. The caudal tongue and palate were exposed by making an incision through the cheek and the laryngeal surface of the epiglottis was exposed by a midline incision from the first tracheal cartilage rostral to the base of the epiglottis. When a single NST neuron was isolated, the location of its receptive field(s) was mapped and responses to mechanical, thermal, and chemical stimuli recorded. The mechanical stimuli consisted of a moving soft brush and glass probe, and punctate stimulation applied using a modified Grass strain gauge. Punctate stimulation ranged from 0.5 to 10 grams. The thermal stimulation sequence was body temperature rinse $\left(37-39^{\circ} \mathrm{C}\right)$, cool rinse $\left(23-25^{\circ} \mathrm{C}\right)$, body temperature rinse, warm rinse $\left(42-43^{\circ} \mathrm{C}\right)$, body temperature rinse. The chemical stimuli applied to the tongue and palate were $0.5 \mathrm{M} \mathrm{KCl}$ and $\mathrm{NH}_{4} \mathrm{Cl}, 0.01 \mathrm{~N} \mathrm{HCl}$, and $0.154 \mathrm{M} \mathrm{NaCl}$. These solutions were dissolved in distilled water, which also served as the rinse. Chemical stimuli applied to the epiglottis were

\footnotetext{
${ }^{a}$ Supported by National Institutes of Health Grant DE05728.
} 
$0.5 \mathrm{M} \mathrm{KCl}$ and $\mathrm{NH}_{4} \mathrm{Cl}, 0.01 \mathrm{~N} \mathrm{HCl}$, and distilled water. The chemical solutions were dissolved in $0.154 \mathrm{M} \mathrm{NaCl}$, which also served as the rinse for the epiglottis.

\section{RESULTS}

Responses were recorded from 53 single NST neurons. Generally, neurons responded to more than one of the stimulus modalities. Thirty-one percent responded to only one, $55 \%$ responded to two, and $14 \%$ responded to all three stimulus types. A greater proportion of neurons with receptive fields on the epiglottis $(93 \%)$ responded to two or three of the stimulus modalities than neurons with oral cavity receptive fields $(36 \%)$. Of the three stimulus modalities tested, mechanical stimuli were the most effective, eliciting responses in $91 \%$ of the neurons. Chemical stimuli produced responses in $60 \%$ of the samples while thermal stimulation was the least effective, eliciting responses from only $32 \%$ of NST neurons. Convergence of afferent information onto NST neurons occurred almost exclusively between the caudal tongue and palate. In these cases, the receptive fields on the tongue were aligned below those located on the palate. TABLE 1 summarizes the types of stimuli responded to on the basis of receptive field location.

Mapping the distribution of recording sites in the NST revealed that neurons with receptive fields located in the caudal oral cavity were generally located rostral, lateral, and ventral in the nucleus compared to those neurons having receptive fields located on the epiglottis.

\section{DISCUSSION}

The presence of large numbers of multimodal neurons suggests that the region of the NST investigated in this study is important in the integration of afferent information produced by complex stimuli in the caudal oral cavity and upper airway. Furthermore, these neurons may provide information important in the initiation of upper airway reflexes. The presence of neurons with opposing tongue and palate receptive fields,

TABLE 1. Percentage of Neurons Responding to Different Stimulus Combinations Classified by Receptive Field Location

\begin{tabular}{lccccc}
\hline \multicolumn{1}{c}{ Stimulus } & $\begin{array}{c}\text { Tongue } \\
\text { Only } \\
(n=9)\end{array}$ & $\begin{array}{c}\text { Palate } \\
\text { Only } \\
(n=4)\end{array}$ & $\begin{array}{c}\text { Epiglottis } \\
\text { Only } \\
(n=28)\end{array}$ & $\begin{array}{c}\text { Tongue and } \\
\text { Palate } \\
(n=9)\end{array}$ & $\begin{array}{c}\text { Other } \\
(n=3)\end{array}$ \\
\hline Mechanical & 67 & 50 & 0 & 56 & 33 \\
Thermal & 0 & 25 & 0 & 0 & 0 \\
Chemical & 0 & 0 & 7 & 0 & 0 \\
Mechanical and thermal & 11 & 25 & 4 & 33 & 0 \\
Mechanical and chemical & 0 & 0 & 60 & 11 & 67 \\
Thermal and chemical & 11 & 0 & 4 & 0 & 0 \\
Mechanical, thermal, and chemical & 11 & 0 & 25 & 0 & 0 \\
\hline
\end{tabular}


which has been reported in other species, ${ }^{2}$ would be particularly well suited for providing information relevant to the manipulation and subsequent swallow of a food bolus. The failure to find convergence in the NST between the widely separated receptor populations of the caudal oral cavity and epiglottis suggests that this peripheral separation is maintained at brainstem levels. This conclusion is further supported by the rough anatomical separation of neurons with oral cavity receptive fields from those having receptive fields on the epiglottis.

\section{REFERENCES}

1. Sweazey, R. D. \& R. M. Bradley. 1986. Central connections of the lingual-tonsillar branch of the glossopharyngeal nerve and the superior laryngeal nerve in lamb. J. Comp. Neurol. 245: 471-482.

2. Hayama, T., S. Ito \& H. Ogawa. 1985. Responses of solitary tract nucleus neurons to taste and mechanical stimulation of the oral cavity in decerebrate rats. Exp. Brain Res. 60: $235-242$. 